\title{
Critical appraisal of 3-monthly paliperidone depot injections in the treatment of schizophrenia
}

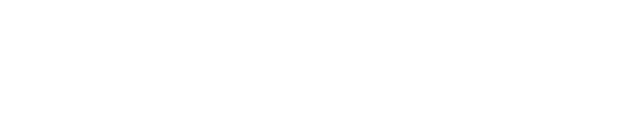

\section{Bernardo Carpiniello Federica Pinna}

Department of Public Health, Clinical and Molecular Medicine - Psychiatry Research Unit and Psychiatric Clinic, University Hospital, Cagliari, Italy
Correspondence: Bernardo Carpiniello Department of Public Health, Clinical and Molecular Medicine - Psychiatry Research Unit and Psychiatric Clinic, University Hospital, Cagliari, Via Liguria 13, 09127 Cagliari, Italy Email bcarpini@iol.it
Aims: Three-monthly injections of paliperidone palmitate (PP-3M) represent a new and recently introduced long-acting antipsychotic therapeutic option. This review focuses on available data relating to the efficacy and safety of PP-3M and its position in the current therapeutic scenario.

Method: An analysis of PubMed, Scopus, and ISI Web of Knowledge databases was conducted, and all available papers on PP-3M, including poster presentations, were selected and considered for the purpose of the present review. Findings: to date, three full papers have been published, the first, a Phase 1 randomized, open label study investigating the pharmacokinetics, safety, and tolerability of the drug; the second, a Phase 3 double blind study vs placebo focusing on efficacy and tolerability; and the last relating to the practical use of PP-3M. The five posters identified describe data reported in the above-cited papers. Overall, the pharmacokinetic findings obtained in these studies highlight the feasibility of administering PP-3M on a 3-monthly basis, subsequent to the administration of four 1-monthly injections of PP at doses 3.5 times higher than the stabilized dose of 1-monthly injections of PP (ie, 175, 300, 450, and $525 \mathrm{mgs}$ ). The published studies highlight a significantly longer time to relapse compared to placebo, and significantly better results compared to placebo for all secondary end-points (Positive and Negative Syndrome Scale, Clinical Global Impression-Severity Scale, Personal and Social Performance Scale scores), in addition to reasonably good safety and tolerability profiles.

Conclusion: PP-3M emerges as a potential candidate for use as a first-line long-acting agent in the maintenance treatment of patients with schizophrenia. Further studies should however be conducted to confirm this expectation. In view of its efficacy, tolerability, and safety, together with the longer timespan between injections, PP-3M currently represents one of the best available options, and may contribute towards addressing the issue of poor adherence, even in early psychosis.

Keywords: long-acting antipsychotics, 3-monthly paliperidone palmitate, efficacy, safety, pharmacokinetics, schizophrenia

\section{Introduction}

Schizophrenia is a severe and chronic disorder, causing significant impairment of functioning and quality of life, at tremendous human and social cost. ${ }^{1}$ The course of this disorder is characterized by periods of largely partial remission alternated with periods of relapse in approximately three quarters of all cases: the estimated relapse rate over 7-12 months following clinical stabilization in patients continuing antipsychotic medications is $27 \% ;^{2}$ approximately $80 \%$ of patients relapse within 5 years of the initial episode, ${ }^{3}$ with no more than $20 \%$ of subjects recovering completely after the first episode. ${ }^{4}$ Relapses frequently lead to hospitalization, poor treatment response, and further worsening of functioning. ${ }^{5}$ Following a relapse, one in six patients fails 
to respond to treatment, and one in ten commits suicide, ${ }^{6}$ symptomatic remission rates, evaluated according to defined strict criteria, are as low as 23\% among chronic and/or patients with high recurrence rates. ${ }^{7}$ Episodes of recurrent illness seem to determine a progressive deterioration in the course of the illness. ${ }^{8}$ Indeed, time passed during relapses appears to be associated with a loss of gray and white matter, ${ }^{9}$ while consecutive relapses are related to progressive loss in brain volume. ${ }^{10}$

Taken together, these data indicate how the prevention of relapse is a fundamental target in the treatment of schizophrenia. Unfortunately, an effective continuity of pharmacological treatment is often difficult to achieve, mainly due to poor adherence, ${ }^{11,12}$ manifested in an average of $41 \%$ of patients affected by schizophrenia; in studies adopting more stringent criteria to evaluate treatment adherence, this percentage increases to $50 \%$ of patients. ${ }^{13}$

The problem of non-adherence would seem to be unrelated to the length of treatment, and generally occurs at a very early stage; it has been demonstrated that 30 days after discharge from hospital, less than $50 \%$ of patients prescribed antipsychotic treatment were adherent. ${ }^{14}$ One of the major consequences of non-adherence is an increased risk of relapse, being approximately five times greater among patients who discontinue treatment. ${ }^{14}$ However, a multitude of other consequences should also be taken into consideration, including increased risk of hospitalization, incomplete remission, impaired functioning, lower quality of life, suicidality and self-harm behavior, aggressivity, substance misuse, and increased costs of treatment. ${ }^{11,12}$ Although a series of strategies has been developed to manage non-adherence, including accuracy in prescribing, or psychosocial interventions including psychoeducation, behavioral or cognitive interventions, and motivational interviewing, ${ }^{11}$ the use of long-acting injections of antipsychotics (LAI) is probably the most widely used and simplest approach to combat non-adherence in common clinical practice, although use is generally limited to subjects who are partially or totally non-compliant to oral treatments. ${ }^{15,16}$ However, the benefits of LAI are not restricted solely to overcoming the problem of non-adherence, and due consideration should be given to the fact that they permit the physician to identify true lack of response (often difficult to evaluate in the case of partial or total non-adherence to oral treatments) and may foster more regular contact with caregivers. Moreover, they determine a better bioavailability, avoid first pass metabolism, establish more stable concentrations and a more predictable correlation between dosages and plasma levels, and reduce the risk of voluntary overdose. ${ }^{17}$
Although the ability of long-acting antipsychotics to enhance treatment adherence ${ }^{18,19}$ is widely acknowledged, there is still considerable ongoing debate with regard to the efficacy of depot vs oral antipsychotics. Indeed, one metaanalysis ${ }^{20}$ demonstrated the superior efficacy of long-acting vs oral antipsychotics in reducing relapse, but a more recent meta-analysis study failed to demonstrate this difference, although a subgroup analysis yielded evidence of the greater effectiveness of long-acting first generation antipsychotics over oral drugs, but only when studies conducted up to 1991 were considered. ${ }^{21}$ However, the results of randomized controlled trials (RCTs) taken into account in meta-analyses should be read in light of several limitations, ${ }^{22}$ which may lead to a bias in favor of oral antipsychotics. In particular, it should be kept in mind that patient samples selected for RCTs are not truly representative of patients seen in the "real world" of common clinical practice due to the presence of exclusion criteria (high severity, previous treatment resistance, relevant psychiatric comorbidity, suicidality etc). Moreover, the higher probability of partially adherent patients being excluded, or being more reluctant to take part in a clinical trial, should be taken into account.

Furthermore, even the most recent meta-analyses ${ }^{21}$ do not include the recently approved second generation long-acting antipsychotics administered by means of a once-monthly injection (paliperidone palmitate $[\mathrm{PP}]$ and aripiprazole). The so-called "mirror image studies" are considered methodologically more appropriate in evaluating comparative effectiveness of antipsychotic formulations; it is worth mentioning that a recent meta-analysis of mirror image studies demonstrated the superiority of LAI over oral antipsychotics in preventing hospitalization. ${ }^{23}$ Nevertheless, evidence from mirror image studies should also be interpreted with caution in view of the major methodological limitation constituted by the lack of control groups. The findings of observational studies based on large administrative databases generally confirm the greater benefits afforded by LAI vs oral antipsychotics; in particular, a very recent study in the USA conducted on an extensive Medicaid multisite database of 3,768 patients who had received antipsychotics following discharge from hospital, ${ }^{19}$ demonstrated that LAI initiators displayed a lower odds of being non-adherent, and were characterized by continuous 60-day gaps between hospitalizations (only patients receiving second generation long-acting antipsychotics) compared to patients taking oral medication.

On the whole, available data support the notion that LAI antipsychotics are at least more effective than oral medications in preventing more severe relapses requiring hospitalization. Several LAI antipsychotic formulations are available 
for the treatment of schizophrenia, both first generation (haloperidol, fluphenazine, flupentixol, pipotiazine zuclopenthixol), and second generation antipsychotics (risperidone, olanzapine, paliperidone, aripiprazole). This affords a greater choice of therapeutic options if long-acting treatment is viewed as the most appropriate in light of the patient's needs and characteristics. Once-monthly PP (PP-1M) is a second generation LAI agent, the efficacy, tolerability, and patient acceptability of which has been demonstrated in a relevant number of short- and long-term studies, both RCTs and open label studies. ${ }^{24}$ The present paper aims to review data published to date relating to the formulation, pharmacokinetics (PK), pharmacodynamics, efficacy, safety, and acceptability of a new formulation of 3-monthly injections of PP (PP-3M), the newest LAI antipsychotic featuring the longest duration of action currently available.

\section{Methods}

An electronic search of PubMed, ISI Web of Knowledge, and Scopus databases, without any time or language restriction, was performed up to November 31, 2015, using "Paliperidone Palmitate 3-Month", "Paliperidone Palmitate 3-month formulation" or "Paliperidone Palmitate 3-month injection" as keywords (Figure 1). References listed in selected papers were checked with the aim of identifying other potentially relevant papers. Poster presentations were specifically taken into account when data presented had not been published in full text articles. USA package inserts (PIs) were consulted for any useful information not published elsewhere.

\section{Results}

Three papers and five posters were thus identified. The first paper reported the results of a Phase 1, single dose, randomized, open label study conducted to investigate the PK, safety, and tolerability of PP-3M in patients with schizophrenia, ${ }^{25}$ the second paper focused on the efficacy and safety of PP-3M emerging from a four phase $\mathrm{RCT}^{26}$ (Table 1), whilst the third related to practical issues implicated in the dosing and switching from PP-1M to PP-3M. ${ }^{27}$ Of the five posters retrieved, two $\mathrm{O}^{28,29}$ reported data from the randomized clinical trials more

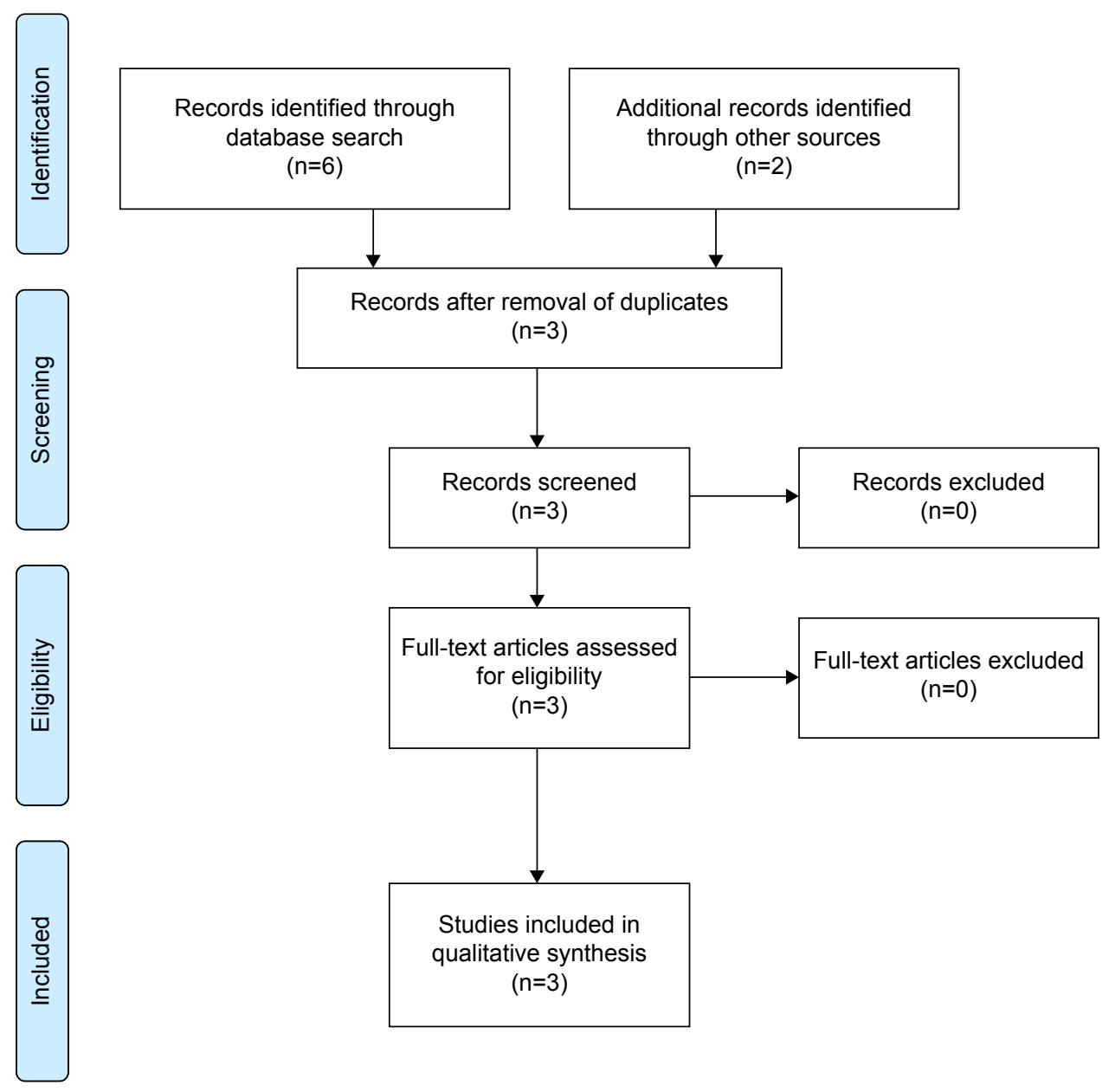

Figure I Literature search flow diagram. 
Table I Summary of clinical studies

\begin{tabular}{|c|c|c|c|c|}
\hline $\begin{array}{l}\text { Study } \\
\text { (authors, } \\
\text { reference) }\end{array}$ & Aims & Design & Sample & Main findings \\
\hline $\begin{array}{l}\text { Berwaerts } \\
\text { et al, }{ }^{26} 2016\end{array}$ & $\begin{array}{l}\text { To evaluate the efficacy } \\
\text { and safety of the 3-monthly } \\
\text { injections of paliperidone } \\
\text { palmitate (PP-3M) vs placebo } \\
\text { in delaying time to relapse of } \\
\text { schizophrenia symptoms }\end{array}$ & $\begin{array}{l}\text { Randomized, multicenter } \\
\text { trial; four phases: 3-week } \\
\text { screening phase; flexible } \\
\text { dose I-week open label } \\
\text { transition phase; I2-week } \\
\text { open label maintenance } \\
\text { phase; open ended double } \\
\text { blind phase }\end{array}$ & $\begin{array}{l}506 \text { patients enrolled, } \\
\text { DSMIV-TR diagnosis } \\
\text { of schizophrenia; } 305 \\
\text { randomized to PP-3M } \\
(n=160) \text { or placebo } \\
(n=145) \text { in the double } \\
\text { blind phase }\end{array}$ & $\begin{array}{l}\text { Time to first relapse differed } \\
\text { significantly, favoring PP-3M group } \\
\text { over placebo } \\
\text { During the double blind phase } 62 \% \\
\text { of patients receiving PP-3M and } \\
58 \% \text { of those receiving placebo } \\
\text { had at least one treatment- } \\
\text { emergent adverse event (TEAE); } \\
\text { TEAEs observed significantly } \\
\text { more frequently among patients } \\
\text { treated with PP-3M compared to } \\
\text { placebo included: headache ( } 9 \% \text { vs } \\
4 \%) ; \text { weight increase ( } 9 \% \text { vs } 3 \%) ; \\
\text { nasopharyngitis (6\% vs I\%); and } \\
\text { akathisia (4\% vs } 1 \% \text { ) }\end{array}$ \\
\hline $\begin{array}{l}\text { Ravenstijn } \\
\text { et al, }{ }^{25} 2015\end{array}$ & $\begin{array}{l}\text { Evaluation of } \\
\text { pharmacokinetics, safety } \\
\text { and, tolerability of PP-3M } \\
\text { in patients affected } \\
\text { by schizophrenia or } \\
\text { schizoaffective disorder }\end{array}$ & $\begin{array}{l}\text { Multicenter, randomized, } \\
\text { open label, parallel-group, } \\
\text { Phase I study }\end{array}$ & $\begin{array}{l}328 \text { patients enrolled, } \\
\text { affected by DSMIV-TR } \\
\text { diagnosis of schizophrenia } \\
\text { or schizoaffective disorder }\end{array}$ & $\begin{array}{l}\text { Peak paliperidone plasma } \\
\text { concentration achieved between } \\
23 \text { and } 34 \text { days; apparent half-life } \\
\text { was } 2-4 \text { months; mean plasma } \\
\text { AUC, and } C_{\text {max }} \text { appeared to } \\
\text { be dose-proportional; relative } \\
\text { bioavailability compared } \\
\text { to paliperidone was } 100 \% \text {, } \\
\text { independent of the dose and } \\
\text { site of injection; headache and } \\
\text { nasopharyngitis were the most } \\
\text { common }(>7 \%) \text { TEAEs }\end{array}$ \\
\hline
\end{tabular}

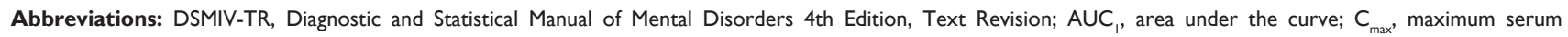
concentration.

extensively described in a paper by Berwaerts et al; ${ }^{26}$ the others ${ }^{30-32}$ reported data more extensively described in a paper by Ravenstijn et al. ${ }^{25}$ For the purpose of the present review, the main findings relating to the formulation, pharmacodynamics and PK, safety, tolerability, and efficacy of PP-3M will be described, followed by the presentation of practical issues encountered while using this new formulation. The review will conclude with considerations of the position occupied by PPM-3M in the current therapeutic scenario.

\section{PP-3M formulation}

PP-3M is a new formulation of the palmitate salt ester of paliperidone (9-OH risperidone) based on a nanocrystal technology similar to that of PP-1M. Nanoparticles are usually defined as having a size between 1-1,000 nm. Tiny drug crystals are created and dispersed in an aqueous suspension (nanosuspensions). The only difference between PP-3M and $\mathrm{PP}-1 \mathrm{M}$ is the increased particle size of the former, ${ }^{25}$ which provides an extended sustained release of paliperidone, allowing a significantly higher dosing interval. In the same way as PP-1M, PP-3M is an admixture of PP enantiomers "wet milled" into nanoparticles characterized by a very low water solubility. These nanoparticles dissolve slowly after intramuscular (IM) injection before being hydrolyzed to paliperidone and adsorbed into the systemic circulation.

\section{Pharmacodynamics}

The putative mechanism of action of PP-3M in schizophrenia, similar to all other formulations of paliperidone, is elicited through a combined central dopamine antagonism on $\mathrm{D}_{2}$ and serotonin $5 \mathrm{HT}_{2 \mathrm{~A}}$ receptor antagonism. Paliperidone displays $\alpha_{1}, \alpha_{2}$, and $H_{1}$ antagonistic properties, but has no significant effect on cholinergic (muscarinic) and $\beta_{1}$ or $\beta_{2}$ receptors. ${ }^{33}$

\section{PK}

Nanoparticles of PP-3M dissolve slowly after IM injection before being hydrolyzed to paliperidone and adsorbed into the systemic circulation; release starts as early as day 1 and lasts for up to 18 months. ${ }^{33}$ In a study by Ravenstijn et al, ${ }^{25}$ consisting of two open label periods after a 21-day screening phase, during the first week patients affected by schizophrenia or schizoaffective disorder according to Diagnostic and Statistical Manual of Mental Disorders 4th Edition, Text Revision (DSMIV-TR) who had not previously taken risperidone or 
paliperidone ( $\mathrm{n}=328$, aged $18-65$ years) received a $1 \mathrm{mg}$ dose of paliperidone immediate release solution in a single IM (gluteal or deltoid) injection; during the second period, which followed a washout period of 7-21 days, patients received different doses (175, 300, 450, and $525 \mathrm{mgs})$ of PP-3M. Peak PP-3M was achieved between 23 and 34 days, with an apparent half-life of 2-4 months, longer than that usually observed after PP-1M, a finding which substantiated the longer dosing interval of 3 months; mean area under the curve $\left(\mathrm{AUC}_{1}\right)$ and maximum serum concentration $\left(\mathrm{C}_{\max }\right)$ appeared to be doseproportional with both gluteal and deltoid injection.

The site of injection was found to be an important factor in the PK of IM injections of PP. Indeed, following administration of PP-3M, the $\mathrm{C}_{\max }$ of paliperidone was $27 \%$ higher in deltoid injection, with no difference in $\mathrm{AUC}_{1}$ between injection sites. These results, strikingly similar to those obtained with PP-1 M, ${ }^{34}$ are due to a difference in absorption rate likely caused by the adipose tissue overlying the gluteal muscle, with a consequent slower than usual uptake of PP following deltoid injection. Ravenstijn et $\mathrm{al}^{25}$ suggested that these intra-injection site differences are not likely to be of clinical significance in view of the fact that PP-3M is designed to be administered only after four or more previous PP-1M injections, when plasma levels are nearing steady-state concentrations. Minimal quantities of the prodrug were detected in $3 \%$ of patients after IM injection of PP-3M, a finding underlining how negligible amounts of the intramuscularly administered product reach the systemic circulation, and confirming that paliperidone is available only after cleavage. According to the authors of the same study, ${ }^{25}$ the PK parameters they observed differed only slightly compared to those cited in the USA $\mathrm{PI}^{33}$ based on findings obtained from the pooled population of Phase 1 and 3 studies. Pharmacokinetic data collected during an efficacy and safety randomized controlled study published recently ${ }^{26}$ are reported as supplementary material; median plasma concentrations of paliperidone during the double blind (DB) phase after PP-3M injections overlapped with plasma concentrations observed in the transition phase (TP) after corresponding PP-1M injections for all dose groups (50 mg equivalents [eq] PP-1M vs 175 mg eq PP-3M; 75 mg eq PP-1M vs 263 mg eq PP-3M; $100 \mathrm{mg}$ eq PP-1M vs $350 \mathrm{mg}$ eq group).

According to the PI, ${ }^{33}$ following a single IM dose of PP-3M, plasma concentrations of paliperidone gradually increase, reaching maximum plasma concentrations at a median time to maximum plasma concentration $\left(\mathrm{T}_{\max }\right)$ of 30-33 days; injections in the deltoid muscle, on average, were determined to have an $11 \%-12 \%$ higher $\mathrm{C}_{\max }$. The release profile and dosing regimen of PP-3M have resulted in sustained concentrations over 3 months. The total and peak exposure of paliperidone after PP-3M administration was dose-proportional over a $273-819 \mathrm{mg}$ dose range. The mean steady-state trough:peak ratio for a dose of PP-3M was 1.6 after gluteal, and 1.7 after deltoid injection. The apparent volume of distribution is $1,960 \mathrm{~L}$ and plasma protein binding is $74 \%$. The reported median half-life of paliperidone following a dose range of $272-819 \mathrm{mg}$ PP-3M IM is comprised between $84-95$ days when injected in the deltoid, and 118-139 days for gluteal injections. At a dose of $819 \mathrm{mg}$ of PP-3M, plasma concentrations detected 18 months after the last dose were $3 \%$ and $7 \%$, respectively, the average steadystate levels following deltoid and gluteal injections.

With regard to metabolism and elimination, $\mathrm{PI}^{33}$ reports information from studies relating to oral PP: approximately $59 \%$ of a single dose of the drug is excreted unchanged in the urine; approximately $80 \%$ of the radioactivity related to a single oral dose of ${ }^{14} \mathrm{C}$ paliperidone was recovered in the urine and $11 \%$ in the feces, indicating a lack of extensive hepatic metabolization. Results obtained in in vitro studies have suggested that CYP2D6 and CYP3A4 may be implicated in the metabolism of PP, although no evidence of their role derived from in vivo studies has been reported. Due to the lack of specific drug interaction studies relating to PP-3M, data reported in $\mathrm{PIs}^{33}$ are derived from studies investigating oral PP, showing a substantial lack of evidence from in vivo studies in support of the hypothesis that inhibitors or inducers of CYP2D6 and CYP3A4 may significantly influence PP plasma levels; moreover, no significant induction or inhibitory properties of PP on the cytochrome system have been demonstrated. Analogously, data obtained in special populations or conditions are largely based on studies of oral $\mathrm{PP}:{ }^{33}$ no significant modifications of plasma concentrations of the drug have been reported based on age, slight/moderate hepatic impairment or smoking, although slower absorption rates were found among females; following PP-3M injections no differences in plasma levels were reported at apparent steady-state between sexes. Similarly, although a lower $\mathrm{C}_{\max }$ was found in overweight and obese subjects, at apparent steady-state with PP-3M, no weight-related differences in plasma levels were revealed. Finally, a comparison of PP-3M with other PP formulations ${ }^{33}$ found that PP-3M, when administered at doses 3.5 -fold higher than the corresponding dose of PP-1M, resulted in paliperidone exposures similar to those of a corresponding PP-1M dose, or a corresponding daily dose of PP extended-release tablets.

\section{Efficacy}

Efficacy of PP-3M vs placebo was evaluated in a multicenter RCT conducted in eight countries on 506 patients 
(aged 18-70 years) affected by schizophrenia according to DSMIV-TR. Ninety-one percent $(n=462)$ of patients enrolled were receiving psychotropic medication before enrollment: $63 \%(n=318)$ oral atypical antipsychotics, $23 \%(n=118)$ typical antipsychotics, and 18\% $(n=89)$ depot antipsychotics $(7 \%, N=36, P P-1 M)$. The study consisted of four phases: a 3-week screening phase, a flexible-dose open label TP, a 12-week open label maintenance phase (MP), and a oneended DB phase.

During the TP patients were treated with PP-1M doses $(50,75,100$ or $150 \mathrm{mg}$ eq), with the exception of subjects switching from other LAI, or those previously treated with PP-1M prior to recruitment to the study. At the start of MP patients received a single dose of PP-3M (deltoid or gluteal) 3.5-fold higher than the stabilized dose of PP-1M during MP, ie, $175,263,350$, and $525 \mathrm{mg}$ eq. In the DB phase, 305 of the 506 patients enrolled were randomized to PP-3M and 145 to placebo. Patients entering the DB phase were aged 38 years, predominantly male (75\%) and white (64\%), previously hospitalized once or more during their lifetime (64\%), with a mean body mass index of $\sim 26$, who had not been on depot prior to the start of the study (83\%).

Patients' clinical severity at the start of DB phase was mild (mean total Positive and Negative Syndrome Scale score 54.5, mean Clinical Global Impression-Severity Scale total score 2.7; mean Personal and Social Performance Scale [PSP] score 68.7). The primary efficacy variable was time from randomization to first relapse. The protocol envisaged an interim efficacy analysis after 42 episodes of relapse and a final analysis after 70 episodes of relapse, if the study had not been terminated previously at interim efficacy analysis. Interim analysis of 284 patients (PP-3M n=148, placebo $\mathrm{n}=135$ ) revealed a significant difference between the two groups, with a median time to relapse of 274 days for the placebo group, which was not estimable for the PP-3M group (hazard ratio $=3.45,95 \%$ confidence interval 1-73-6.88, $P<0.001)$. Twenty-three percent of subjects receiving placebo $(n=31)$, and $7 \%(n=11)$ of those receiving PP-3M were relapsing. Based on these findings, an independent committee recommended early termination of the study for efficacy.

At the time of final analysis of the entire sample ( $n=305$ patients), the superiority of PP-3M vs placebo in delaying time to relapse (hazard ratio $=3.81,95 \%$ confidence interval 2.08-6.99, $P<0.001)$ was confirmed, with a median time to relapse, which was not estimable for PP-3M patients, and of 395 days for the placebo group. According to final analysis, 29\% of the placebo group $(n=42)$ and $9 \%$ of the PP-3M group $(n=14)$ were relapsing. A higher efficacy of
PP-3M over placebo was demonstrated irrespective of age, sex, race, body mass index or study site. Out of all patients randomized in the DB phase, $50 \%$ of $\mathrm{PP}-3 \mathrm{M}$ and $57 \%$ of placebo patients were remitted at DB baseline. Ninety-two percent of subjects receiving PP-3M were still in remission at week 36 compared to $58.3 \%$ of those receiving placebo. A decreased number of well-functioning patients (PSP total score $>70$ ) was detected in the placebo group (from $42 \%$ at DB baseline to $32 \%$ at end-point), while PP-3M patients remained fairly stable $(46 \%$ both at baseline and end-point). A number of secondary efficacy analyses supported the higher efficacy of PP-3M over placebo. Indeed, significant differences in mean variation from DB baseline to end-point were observed in scores obtained in several rating scales by patients receiving $\mathrm{PP}-3 \mathrm{M}$ compared to the placebo group (Table 2).

\section{Safety}

In the study by Ravenstijn et $\mathrm{al}^{25}$ during period 2 , when a single dose of PP-3M was injected, $73.7 \%$ of patients experienced at least one treatment-emergent adverse event (TEAE), the majority of which were rated as mild or moderate; taking into account the summary of data from all study panels, the most common included nasopharyngitis (11\%), headache (9\%), psychotic disorder or schizophrenia (6.2\%), weight increase $(5.2 \%)$, and back pain $(5.2 \%)$ (Table 3$)$. In the study by Bewaerts et al, ${ }^{26} 65 \%$ of patients in the open label phase $(n=330$ over 506$)$ and 60\% (183 over 305 patients) in DB phase ( $62 \%$ of those on PP-3M, $58 \%$ of the placebo group) displayed at least one TEAE.

When considering only the most frequently manifested events, during the MP patients receiving PP-3M reported anxiety $(6 \%)$, and insomnia (5\%); very few patients discontinued treatment, three $(1 \%)$ due to "psychiatric disorders" and one $(0.3 \%)$ due to "schizophrenia". During the DB phase, compared to the placebo group, the most frequently manifested TEAEs in PP-3M treated patients were a higher than $7 \%$ weight increase ( $10 \%$ vs $1 \%$ ), headache ( $9 \%$ vs $4 \%$, respectively), extrapyramidal symptoms (EPS) (8\% vs 3\%, respectively), including akathisia (4\% vs 1\%, respectively), and nasopharyngitis ( $6 \%$ vs $1 \%$, respectively). On the contrary, the most frequent TEAEs manifested by placebo-treated patients compared to those taking PP-3M were anxiety (11\% vs $8 \%$, respectively), insomnia (12\% vs 7\%, respectively), weight loss ( $8 \%$ vs $1 \%$ ), and glucose-related TEAEs (6\% vs 3\%) (Table 4$)$. With regard to electrocardiography findings, abnormally elevated heart rate was detected in $7 \%$ vs $3 \%$ of patients, respectively. Patients with a change in QTc interval $>30-60 \mathrm{msec}$ from DB baseline 
Table 2 Change from baseline mean scores of clinical and functioning scales in patients treated with PP-3M vs placebo*

\begin{tabular}{|c|c|c|c|}
\hline Scales (mean, SD) & Placebo $(n=\mid 45)$ & PP-3M $(n=160)$ & $P$-value \\
\hline \multicolumn{4}{|l|}{ PANSS total score ${ }^{a}$} \\
\hline Baseline & $54.3(9.20)$ & $54.8(9.96)$ & \\
\hline Change from Baseline ${ }^{b}$ & $6.7(14.40)$ & $-0.5(8.36)$ & $<0.001$ \\
\hline \multicolumn{4}{|l|}{ PANSS subscales scores ${ }^{\mathrm{a}}$} \\
\hline \multicolumn{4}{|l|}{ Positive subscale } \\
\hline Baseline & II.4 (2.99) & II.7 (3.20) & \\
\hline Change from Baseline ${ }^{b}$ & $2.7(4.92)$ & $-0.1(2.84)$ & $<0.001$ \\
\hline \multicolumn{4}{|l|}{ Negative subscale } \\
\hline Baseline & $16.2(3.91)$ & $16.4(4.42)$ & \\
\hline Change from Baseline ${ }^{b}$ & $0.8(3.76)$ & $-0.1(2.96)$ & 0.013 \\
\hline \multicolumn{4}{|c|}{ General psychopathology subscale } \\
\hline Baseline & $26.6(4.92)$ & $26.8(4.98)$ & \\
\hline Change from Baseline ${ }^{\mathrm{b}}$ & $3.2(7.88)$ & $-0.3(4.77)$ & $<.001$ \\
\hline \multicolumn{4}{|c|}{ PANNS Marder standardized factor scores ${ }^{\mathrm{a}}$} \\
\hline \multicolumn{4}{|l|}{ Positive symptoms } \\
\hline Baseline & $14.6(3.7 \mid)$ & 14.9 (3.72) & \\
\hline Change from Baseline ${ }^{b}$ & $2.5(5.25)$ & $-0.1(2.74)$ & $<0.001$ \\
\hline \multicolumn{4}{|l|}{ Negative symptoms } \\
\hline Baseline & $15.0(3.70)$ & I5.2 (4.28) & \\
\hline Change from Baseline ${ }^{b}$ & $0.4(4.01)$ & $-0.3(3.21)$ & 0.080 \\
\hline \multicolumn{4}{|l|}{ Disorganized thought } \\
\hline Baseline & $13.8(3.25)$ & | $3.8(3.4 \mid)$ & \\
\hline Change from Baseline ${ }^{b}$ & $0.7(3.38)$ & $-0.2(2.53)$ & 0.005 \\
\hline \multicolumn{4}{|c|}{ Uncontrolled Hostility/excitement } \\
\hline Baseline & $5.2(1.77)$ & $5.2(1.80)$ & \\
\hline Change from Baseline ${ }^{b}$ & 1.7 (3.18) & $-0-0(1.89)$ & $<0.001$ \\
\hline \multicolumn{4}{|l|}{ Anxiety/depression } \\
\hline Baseline & $5.7(2.02)$ & $5.8(2.10)$ & \\
\hline Change from Baseline ${ }^{b}$ & $1.4(3.28)$ & $0.1(2.34)$ & $<0.001$ \\
\hline \multicolumn{4}{|l|}{ CGI-S score ${ }^{a}$} \\
\hline Baseline & $2.8(0.65)$ & $2.7(60.68)$ & \\
\hline Change from Baseline ${ }^{b}$ & $0.4(0.87)$ & $0.1(0.60)$ & $<0.001$ \\
\hline \multicolumn{4}{|l|}{ PSP total score ${ }^{a}$} \\
\hline Baseline & $68.5(8.93)$ & $68.9(9.34)$ & \\
\hline Change from Baseline $^{c}$ & $-4.2(9.70)$ & $-0.5(6.63)$ & $<0.001$ \\
\hline
\end{tabular}

Notes: *Based on analysis of covariance (ANCOVA) model with treatment (placebo, PP-3M) and country as factors and baseline value as a covariate. ${ }^{\mathrm{a}}$ Explanation of scores: decrease in PANSS scores and CGI-S scores indicate improvement. Decrease in PSP scores indicate worsening. ${ }^{\text {bPlacebo }(n)=142 ; P P-3 M(n)=159 .{ }^{c} P l a c e b o}(n)=142 ;$ PP-3M $(n)=157$. Reproduced with permission from JAMA Psychiatry. 2015. 72(8). doi: 10100I/jamapsychiatry. ${ }^{26}$ Copyright $@ 2015$ American Medical Association. All rights reserved. Abbreviations: PP-3M, 3-monthly injections of paliperidone palmitate; PANSS, Positive and Negative Syndrome Scale; CGI-S, Clinical Global Impression-Severity Scale; PSP, Personal and Social Performance Scale; SD, standard deviation.

records ranged from $3.2 \%$ to $6.9 \%$ among patients receiving PP-3M and from $2.8 \%$ to $5.5 \%$ among placebo-treated subjects, according to the different formula utilized for calculation of QTc. An increase of QTc > 60 msec was observed in only one patient $(<1 \%)$ treated with PP-3M during the open label (OL) phase, and no patients manifested a QTc increase over $480 \mathrm{msec}$ at any point in the study.

With regard to weight, the mean increase from OL baseline (which included the OL TP, characterized by several doses of PPM-1M followed by one single dose of PP-3M) and to DB end-point was significantly higher among patients treated with PP-3M compared to placebo (2.38 vs $0.55 \mathrm{~kg}$, respectively). A few TEAEs were registered in PM-3M patients alone: injection site TEAE (4\%, of which $2 \%$ was pain), prolactin increase (1\%), and amenorrhea (2\%). To summarize, serious TEAEs were registered with an approximately 4-fold higher frequency in the placebo group compared to PP-3M group $(10 \%$ vs $3 \%$, respectively), and were generally represented by worsening of psychiatric symptoms, with only one hepatic TEAE (increased transaminase level) leading to treatment discontinuation in the DB phase in the placebo group; one patient treated with PP-1M died during the open label phase due to complications from megacolon, a death which was not deemed to be related to the study drug. Overall, discontinuation due to adverse events occurred in $5.1 \%$ of patients during the long-term, open label, MP, with no discontinuation during the DB phase. 
Table 3 Treatment-emergent adverse events $5 \%$ in any treatment group

\begin{tabular}{|c|c|c|c|c|c|c|c|c|}
\hline & \multicolumn{2}{|l|}{ Panel A } & \multicolumn{2}{|l|}{ Panel B } & \multicolumn{2}{|l|}{ Panel C } & \multicolumn{2}{|l|}{ Panel D } \\
\hline & $\begin{array}{l}\text { Period I } \\
\mathbf{N}=72\end{array}$ & $\begin{array}{l}\text { Period } 2 \\
N=66\end{array}$ & $\begin{array}{l}\text { Period I } \\
N=128\end{array}$ & $\begin{array}{l}\text { Period } 2 \\
N=120\end{array}$ & $\begin{array}{l}\text { Period I } \\
\mathbf{N}=\mathbf{2 5}\end{array}$ & $\begin{array}{l}\text { Period } 2 \\
N=24\end{array}$ & $\begin{array}{l}\text { Period I } \\
N=100\end{array}$ & $\begin{array}{l}\text { Period } 2 \\
\mathbf{N}=98\end{array}$ \\
\hline Patients with at least I TEAEs & $27(37.5)$ & $49(74.2)$ & $40(31.2)$ & $99(82.5)$ & $5(20)$ & $18(75)$ & $15(15)$ & $61(62.2)$ \\
\hline Nasopharyngitis & $\mathrm{I}(\mathrm{I} .4)$ & $9(13.6)$ & - & $15(12.5)$ & - & - & - & $10(10.2)$ \\
\hline Headache & $4(5.6)$ & $9(13.6)$ & $6(4.7)$ & I4 (I I.7) & $2(8.0)$ & $4(16.7)$ & $2(2.0)$ & $7(7.1)$ \\
\hline Weight increased & I (I.4) & $2(3.0)$ & $2(1.6)$ & $9(7.5)$ & - & - & $2(2.0)$ & $5(5.1)$ \\
\hline Back pain & - & - & - & $8(6.7)$ & - & $2(8.3)$ & I (I.0) & $6(6.1)$ \\
\hline Anxiety & $2(2.8)$ & $2(3.0)$ & $4(3.1)$ & $12(10.0)$ & - & - & - & - \\
\hline Tootache & I (I.4) & $4(6.1)$ & I (0.8) & $9(7.5)$ & - & - & - & $4(4.1)$ \\
\hline Psychotic disorder & - & $3(4.5)$ & - & $6(5.0)$ & - & - & - & $4(4.1)$ \\
\hline Diarrhea & I (I.4) & $3(4.5)$ & $2(1.6)$ & $9(7.5)$ & - & - & - & - \\
\hline Insomnia & $4(5.6)$ & $3(4.5)$ & I (0.8) & $9(7.5)$ & - & - & - & - \\
\hline Depression & - & $3(4.5)$ & - & $6(5.0)$ & - & - & - & $2(2.0)$ \\
\hline Tachycardia & I (I.4) & $2(3.0)$ & - & $7(5.8)$ & - & - & - & $2(2.0)$ \\
\hline Abdominal pain & - & $2(3.0)$ & I (0.8) & $8(6.7)$ & - & - & - & - \\
\hline Weight loss & - & - & - & $7(5.8)$ & - & - & - & - \\
\hline Upper Respiratory Tract & - & - & - & $3(2.5)$ & - & $6(25.0)$ & - & - \\
\hline \multicolumn{9}{|l|}{ infections } \\
\hline Schizophrenia & - & - & I (0.8) & $6(5.0)$ & - & - & - & - \\
\hline Vomiting & - & - & - & - & - & $2(8.3)$ & - & - \\
\hline Warmness injection site & - & - & - & - & - & $2(8.3)$ & - & - \\
\hline Diabetes mellitus & - & - & - & - & - & $2(8.3)$ & - & - \\
\hline
\end{tabular}

Notes: Data shown as $\mathrm{n}(\%)$, treatment emergent adverse events. Phase 2: Panel A, $300 \mathrm{mg}$ eq PP-3M, im (gluteal); panel B, 75 , I50 or $450 \mathrm{mg}$ eq PP-3M, im (gluteal) or 300 or $450 \mathrm{mg}$ eq PP-3M, im (deltoid); panel C, $150 \mathrm{mg}$ eq PP-3M, im (gluteal); panel D, $175 \mathrm{mg}$ eq (deltoid), $350 \mathrm{mg}$ eq (gluteal), or $525 \mathrm{mg}$ eqPP-3M, im (deltoid). During period I patients (all panels) received a single dose intramuscular injection of I mg paliperidone IR (immediate release) solution; during period 2 patients (all panels) received a single dose intramuscular injection of PP-3M. Reproduced from Ravenstijn P, Remmerie B, Savitz A, et al. Pharmacokinetics, safety, and tolerability of paliperidone palmitate 3-month formulation in patients with schizophrenia: A phase-I, single-dose, randomized, open-label study. J Clin Pharmacol. 20I6;56(3):330-339,25 John Wiley and Sons. Copyright @20I5. Abbreviations: PP-3M, 3-monthly injections of paliperidone palmitate; TEAEs, treatment-emergent adverse events.

\section{Practical issues for dosing and switching}

Based on published studies, Gopal et $\mathrm{al}^{27}$ have provided guidance for the practical use of PP-3M. In particular, switching to $\mathrm{PP}-3 \mathrm{M}$ is only recommended in patients who have previously been treated with PP-1M for at least 4 months; the first injection should be given at the time of the first scheduled administration of PP-1M, with a dosing window of \pm 1 week. A dose of PP-3M corresponding to 3.5 times the last dose of PP-1M, ie, $175 \mathrm{mg}$ eq of PP-3M substitute; $70 \mathrm{mg}$ eq of PP-1M, should be administered. Following the first injection, PP-3M should be given once every 3 months with a dosing window of \pm 2 weeks, resulting in the need for approximately four injections per year. PP-3M doses may be administered in either deltoid or gluteal muscle using a $1.522 \mathrm{G}$ needle, although if deltoid injection is given to a person $<90 \mathrm{~kg}$, a 1.0 inch $22 \mathrm{G}$ needle would be preferable. In the case of mild renal impairment, evidenced by creatinine clearance ranging between 50 and $80 \mathrm{~mL} / \mathrm{min}$, a 25\% dose reduction of PP-1M should be applied, with a subsequent switch to a 3.5 fold higher dose of PP-3M, which should not exceed the maximum dose of $350 \mathrm{mg}$ eq. In elderly subjects with reduced renal function (limited to mild impairment) a similar adjustment of dosing is recommended. The use of PP-3M in patients of any age with moderate/severe renal impairment should be avoided. However, no dose adjustment of PP-3M is required in patients of any age with mild or moderate hepatic impairment, or in elderly patients with normal renal function.

\section{PP-3M: summary of evidence, position in the therapeutic scenario, and future developments}

Introduction of LAI constituted one of the first examples of the efforts made to overcome the problems of non-adherence in an area of psychopathology, such as psychotic disorders, in which very long-term treatments are the general rule. It is an acknowledged fact that adherence can be improved using the currently marketed LAI, although non-compliance continues to persist even when prescribing these formulations. ${ }^{11}$ Thus, continuous research by the pharmaceutical industry aimed at introducing new formulations featuring an extended duration of action is of fundamental importance. Indeed, the main reason underlying the development of PP-3M was to obtain a drug formulation capable of extending dosing intervals in order to reduce non-adherence compared to the other currently available LAI. ${ }^{26}$

The real advantage of this new formulation of PP-3M is the possibility of simplifying the therapeutic regimen as much 
Table 4 Summary of TEAEs reported during the Double-Blind Phase in the Safety Analysis Set ${ }^{\mathrm{a}}$

\begin{tabular}{|c|c|c|}
\hline Variable & $\begin{array}{l}\text { Placebo } \\
(\mathbf{N}=\mid 45) \\
N(\%)\end{array}$ & $\begin{array}{l}\text { 3mo Paliperidone } \\
\text { Palmitate } \mathrm{N}=160 \\
\mathrm{~N}(\%)\end{array}$ \\
\hline Patients with TEAEs & $84(58)$ & $99(62)$ \\
\hline Possibly drug-related TEAE & $27(19)$ & $54(34)$ \\
\hline TEAE leading to drug withdrawal & $I(I)$ & 0 \\
\hline Patients with $\geq$ I serious TEAE & $15(10)$ & $4(3)$ \\
\hline \multicolumn{3}{|l|}{$\begin{array}{l}\text { TEAEs reported in } \geq 2 \% \text { of patients in } \\
\text { either group }\end{array}$} \\
\hline Headache & $6(4)$ & $14(9)$ \\
\hline Anxiety & $16(11)$ & $13(8)$ \\
\hline Insomnia & $17(12)$ & II (7) \\
\hline Nasopharyngitis & $2(I)$ & $9(6)$ \\
\hline Upper Respiratory Tract infections & $3(2)$ & $6(4)$ \\
\hline Cough & $3(2)$ & $5(3)$ \\
\hline Urinary tract infections & $2(1)$ & $6(4)$ \\
\hline Influenza & $3(2)$ & $3(2)$ \\
\hline Schizophrenia & $15(10)$ & $2(1)$ \\
\hline Weight decreased & II (8) & $2(1)$ \\
\hline Agitation & $3(2)$ & $2(1)$ \\
\hline Decreased appetite & $3(2)$ & $I(I)$ \\
\hline Irritability & $3(2)$ & $I(I)$ \\
\hline Suicidal ideation & $3(2)$ & 0 \\
\hline EPS-related TEAEs & $5(3)$ & $13(8)$ \\
\hline Akathisia & $\mathrm{I}(\mathrm{I})$ & $7(4)$ \\
\hline $\begin{array}{l}\text { Diabetes mellitus and hyperglicemia- } \\
\text { related TEAEs }\end{array}$ & $8(6)$ & $4(3)$ \\
\hline Blood glucose level increased & $3(2)$ & $3(2)$ \\
\hline Hyperglicemia & $4(3)$ & 0 \\
\hline Weight gain-related TEAEs & $5(3)$ & $15(9)$ \\
\hline Weight increased & $5(3)$ & $14(9)$ \\
\hline Injection site-related TEAEs & 0 & $6(4)$ \\
\hline Prolactin-related TEAEs & 0 & I (I) \\
\hline Amenorrhea & 0 & I $(2)^{b}$ \\
\hline
\end{tabular}

Notes: aThe TEAEs reported herein occurred in the double-phase; if a patient developed a TEAE during the open-label phase (either transition or maintenance) and the TEAE did not worsen during the double-blind phase, it would not be captured. 'Sample size was 42 women. Reproduced from JAMA Psychiatry. 2015. 72(8), doi:101001/jamapsychiatry.2015.0241,26 Copyright @2015 American Medical Association. All rights reserved.

Abbreviations: EPS, extrapyramidal symptoms; TEAEs, treatment-emergent adverse events.

as possible, with the aim of increasing treatment acceptance by frequently reluctant or otherwise uncooperative patients. Another advantage may be the reduced dosing frequency for patients with limited access to health care. Overall data from published studies clearly indicate the efficacy and safety of PP-3M, substantially similar to that obtained with $\mathrm{PP}-1 \mathrm{M}$ in long-term treatment, and in preventing relapse in patients affected by schizophrenia. ${ }^{34}$ Indeed, PP-3M not only significantly delays the time to recurrence, but has proved capable of further reducing the severity of psychopathology in patients stabilized with PP-3M; moreover, these evident clinical improvements are paralleled by the progressive amelioration of personal and social functioning, as shown not only by the improvement of PSP scores, but also by the large number of patients $(46 \%)$ who, on completion of the DB phase of treatment, maintained the good functioning (ie, a PSP total score $>70$ ) displayed at baseline. ${ }^{26}$

As regards safety and tolerability, ${ }^{25,26}$ the most common adverse events, including EPS and weight gain, are generally manifested in no more than $10 \%$ of cases, being generally of low or moderate severity. Metabolic and cardiologic safety is a finding of noteworthy clinical importance, particularly in view of the almost insignificant rate of severe adverse events. Unfortunately, studies published to date have failed to address the problem of patients' subjective perceptions of the drug, although the very low rate of withdrawal of consent by subjects receiving PP-3M (4\%) both in the maintenance and DB phase may be considered a proxy of more specific measures of personal perception of the drug, indicating a fairly good acceptance of PP-3PM. However, in light of the knowledge that PP-3M is a "young" formulation supported by a limited number of studies, these promising data will need to be confirmed in future research studies. In particular, additional long-term studies should be undertaken to confirm the available data, as occurred previously for PP-1M. ${ }^{34-41}$ In particular, we expect to see further information from "naturalistic" studies, which were pivotal in providing significant confirmation of the effectiveness of PP-1M in "real world" schizophrenic populations, such as those with physical and psychiatric comorbidity, including drug abuse. ${ }^{42-44}$

As mentioned previously, specific concerns are focused on the patient's subjective perception and acceptance of the new formulation; no studies have been conducted to date to verify the latter, although positive results, similar to those emerging from PP-1M studies ${ }^{24}$ may be expected. The use of a very long-term active formulation such as PP-3M may give rise to further concerns among mental health professionals who are critical of the use of these formulations. ${ }^{45}$ In particular, several aspects should be taken into consideration: the risks implicated due to the persistence of side-effects, the risk of a reduced involvement of mental health staff in patient care, the presumed negative appraisal of these formulations by patients, and the coercive nature of this type of care. With regard to the first point, persistence of side effects in subjects in whom the drug is suspended due to safety concerns is fortunately a rare event, as attested by the available safety data relating to severe adverse events in patients treated with LAI, including PP-3M. Regarding the second point, to what extent the use of LAI actually results in a diminishing of clinical care of the patient is a matter of debate, particularly in view of a 
lack of reliable data. It would however seem to be an inherent problem in the professional and educational setting, work ethics, and staff resources of community teams rather than an intrinsic problem linked to LAI therapy. As to the presumed negative appraisal of the drug, data from literature seem to disprove this assumption, as LAI, including PP-1M, are generally well accepted..$^{45}$ Lastly, with regard to the hypothesized coercive nature of LAI, it should be underlined how, as a general ethical principle, all treatment should be given on a voluntary basis, with the sole exception of involuntary treatments provided and regulated by law throughout the majority of countries; the creation of a valid therapeutic alliance, the acquisition of informed consent, and of adequate adherence to treatment is one of the fundamental duties of psychiatrists, and forms the basis of an effective treatment. In our opinion, it is not the drug that is coercive per se, but rather the means adopted in fulfilling a duty of care.

To conclude, with regard to the position occupied by $\mathrm{PP}-3 \mathrm{M}$ in the range of therapeutic options for the treatment of psychoses, LAI have been considered in authoritative guidelines and by leading experts in the field as a fundamental option in the long-term treatment of schizophrenia. ${ }^{46,47}$ Indeed, this type of formulation will likely occupy an extremely relevant position, particularly in view of its singular pharmacokinetic properties and the possibility of simplifying and rendering the process of long-term care more acceptable. However, the risk of LAI being confined to use in the maintenance of only very chronic cases, often being seen as a "last resort" treatment for a large number of psychiatrists, should be discussed. ${ }^{48}$ Several experts on the subject ${ }^{48,49}$ maintain that it may be advisable to consider the issue from another perspective, namely the use of LAI in the early treatment of psychoses, although data from literature reveal that psychiatrists are frequently reluctant to prescribe LAI in general, and particularly for the treatment of first episodes and in young people. ${ }^{50}$

The suggestion to use LAI in the treatment of early psychosis is based upon preliminary evidence attesting the superiority of LAI-second generation antipsychotics over oral second generation antipsychotics in controlling negative symptoms and psychosocial functioning, as well as the potential superiority of LAI in the early detection of high rates of non-adherence in first-episode patients, and consequent reduction of the number of relapses and hospitalizations. ${ }^{50,51}$ Moreover, the opinion widely held by psychiatrists that young people are extremely reluctant to accept depot injections seems to be confuted by the optimal acceptance of therapy shown in a recent study. ${ }^{52}$ Although the paucity of studies available and the methodological limitations of studies relating to LAI in early psychoses do not allow any firm conclusions to be reached, the early use of LAI subsequent to initial episodes seems to be worthy of consideration, at least in early cases displaying a clear problem of non-adherence. Thus, in view of the lower number of injections required, in these cases it is likely reasonable to anticipate an improved acceptance of PP-3M compared to other LAI. Taken together, this potential for improved treatment acceptance and the presence of a reasonably good safety profile contribute towards proposing PP-3M as a first-line therapeutic option.

\section{Disclosure}

BC received grants for research from Astra Zeneca and Lundbeck and honoraria from Astra Zeneca, Janssen-Cilag, Lundbeck, Otsuka, and Pfizer for participation in advisory boards and/or congresses or educational events as a speaker. FP has no conflict of interest to disclose in this work.

\section{References}

1. Van Os J, Kapur S. Schizophrenia. Lancet. 2009;374(9690):635-645.

2. Leucht S, Tardy M, Komossa K, et al. Antipsychotic drugs versus placebo for relapse prevention in schizophrenia: a systematic review and meta-analysis. Lancet. 2012;379(9831):2063-2071.

3. Robinson DG, Woerner DG, McMeniman M, Mendelowitz A, Bilder RM. Symptomatic and functional recovery from a first episode of schizophrenia or schizoaffective disorder. Am J Psychiatry. 2004;161(3): 473-479.

4. Jääskeläinen E, Juola $P$, Hirvonen N, et al. A systematic review and meta-analysis of recovery in schizophrenia. Schizophr Bull. 2013;39(6): 1296-1306.

5. Kane JM. Improving patient outcomes in schizophrenia: achieving remission, preventing relapse and measuring success. J Clin Psychiatry. 2013; 74(9):e18.

6. Wiersma D, Nienhuis FJ, Slooff CJ, Giel R. Natural course of schizophrenic disorders: a 15-year follow-up of a Dutch incidence cohort. Schizophr Bull. 1998;24(1):75-85.

7. Pinna F, Tusconi M, Bosia M, et al. Criteria for symptom remission revisited: a study of patients affected by schizophrenic or schizoaffective disorders. BMC Psychiatry. 2013;13:235.

8. Emsley R, Chiliza B, Asmal L. The evidence for illness progression after relapse in schizophrenia. Schizophr Res. 2013;148(1-3):117-121.

9. Andreasen NC, Liu D, Ziebell S, Vora A, Ho BC. Relapse duration, treatment intensity, and brain tissue loss in schizophrenia: a prospective longitudinal MRI study. Am J Psychiatry. 2013;170(6):609-615.

10. Van Haren NE, Hulshoff Pol HE, Schnack HG, et al. Focal grey matter changes in schizophrenia across the course of illness: a 5-year follow-up study. Neuropsychopharmacology. 2007;32(10):2057-2066.

11. Haddad PM, Brain C, Scott J. Nonadherence with antipsychotic medication in schizophrenia: challenges and management strategies. Patient Relat Outcome Meas. 2014;5:43-62.

12. Higashi K, Medic G, Littlewood KJ, et al. Medication adherence in schizophrenia: factors influencing adherence and consequences of nonadherence: a systematic literature review. Ther Adv Psychopharmacol. 2013;3(4):200-218. 
13. Lacro JP, Bunn LB, Dolder CR, Leckband SG, Jeste DV. Prevalence and risk factors for medication nonadherence in patients with schizophrenia: a comprehensive review of recent literature. J Clin Psychiatry. 2002; 63(10):892-909.

14. Tiihonen J, Haukka J, Taylor M, Haddad PM, Patel MX, Korhonen P. A nationwide cohort study of oral and depot antipsychotics after first hospitalization for schizophrenia. Am J Psychiatry. 2011;168(6): 603-609.

15. Asher-Svanum H, Peng X, Faries D, Montgomery W, Haddad PM. Treatment patterns and clinical characteristics prior to initiating depot typical antipsychotics for nonadherent schizophrenia patients. BMC Psychiatry. 2009;9:46.

16. Heres S, Hamann J, Kissiling W, Leucht S. Attitudes toward antipsychotic depot medication. J Clin Psychiatry. 2006;67(12):1948-1953.

17. Olivares JM, Pinal B, Cinos C. Comparison of long-acting antipsychotics injection and oral antipsychotics in schizophrenia. Neuropsychiatry. 2011;1:275-289.

18. Cañas F, Alptekin K, Azorin JM, et al. Improving treatment adherence in your patients with schizophrenia: the STAY initiative. Clin Drug Investig. 2013;33(2):97-107.

19. Marcus S, Zummo J, Pettit AR, Stoddard J, Doshi JA. Antipsychotic adherence and rehospitalization in schizophrenia patients receiving oral versus long-acting injectable antipsychotics following hospital discharge. J Manag Care Spec Pharm. 2015;21(9):754-768.

20. Leucht C, Heres S, Kane JM, et al. Oral versus depot antipsychotic drugs for schizophrenia - a critical systematic review and meta-analysis of randomized long-term trials. Schizophr Res. 2011;127(1-3):83-92.

21. Kishimoto T, Robenzadeh A, Leucht C, et al. Long-acting injectable vs oral antipsychotics for relapse prevention in schizophrenia: a metaanalysis of randomized trials. Schizophr Bull. 2014;40(1):192-213.

22. Kane JM, Kishimoto T, Correll CU. Assessing the comparative efficacy of long-acting injectable vs oral antipsychotic medications in the prevention of relapses provides a case study in comparative effectiveness research in psychiatry. J Clin Epidemiol. 2013;66 (8 Suppl):S37-S41.

23. Kishimoto T, Nitta M, Borenstein M, Kane JM, Correll CU. Long-acting injectable versus oral antipsychotics in schizophrenia: a systematic review and meta-analysis of mirror-image studies. J Clin Psychiatry. 2013; 74(10):957-965

24. Gonzales-Rodriguez A, Catalan R, Penades R, et al. Profile of paliperidone palmitate once-monthly long acting injectable in the management of schizophrenia: long-term safety, efficacy and patient acceptability a review. Patient Prefer Adherence. 2015;9:695-706.

25. Ravenstijn P, Remmerie B, Savitz A, et al. Pharmacokinetics, safety, and tolerability of paliperidone palmitate 3 -month formulation in patients with schizophrenia: A phase-1, single-dose, randomized, open-label study. J Clin Pharmacol. 2016;56(3):330-339.

26. Bewaerts J, Liu Y, Gopal S, et al. Efficacy and Safety of the 3-Month Formulation of Paliperidone Palmitate vs Placebo for Relapse Prevention of Schizophrenia: A Randomized Clinical Trial. JAMA Psychiatry 2015;72(8):830-839.

27. Gopal S, Vermeulen A, Nandy P, et al. Practical guidance for dosing and switching from paliperidone palmitate 1 monthly to 3 monthly formulation in schizophrenia. Curr Med Res Opin. 2015;31(11): 2043-2054.

28. Berwaerts J, Liu Y, Gopal S, et al. Efficacy and safety of paliperidone palmitate 3 month formulation: a randomized double blind, placebo controlled study [abstract]. Schiz Bull. 2015;41(Supp 1):S302.

29. Berwaerts J, Liu Y, Gopal S, et al. Efficacy and safety of paliperidone palmitate 3 month formulation: a randomized double blind, placebo controlled study. European Psychiatry. 2015;30(Supp 1):272. Abstract.

30. Gopal S, Vermeulen A, Nandy P, et al. Population pharmacokinetic simulations of dosing windows and missed doses of paliperidone palmitate 3-month formulation in schizophrenia [abstract]. Poster presented at: American Psychiatric Association, $168^{\text {th }}$ Annual Meeting; May 16-20, 2015; Toronto, Canada.
31. Samtani MN, Vereulen A, Partha N, et al. Switching scenarios for paliperidone palmitate 3-month formulation in schizophrenia: a population pharmacokinetic simulation-based evaluation. Poster presented at: American Psychiatric Association, $168^{\text {th }}$ Annual Meeting; May 16-20, 2015; Toronto, Canada.

32. Samtani MN, Remmerie B, Savitz A, et al. Pharmacokinetics, safety and tolerability of a single dose of paliperidone palmitate 3-month formulation in patients with schizophrenia [abstract]. American Psychiatric Association, $168^{\text {th }}$ Annual Meeting; May 16-20, 2015; Toronto, Canada.

33. Invega Trinza (paliperdone palmitate extended release injectable suspension for intramuscular use) [package insert]. Titusville, FL: Janssen Pharmaceuticals; 2015.

34. Hough S, Gopal S, Vijapurkar U, et al. Paliperidone palmitate maintenance treatment in delaying the time-to-relapse in patients with schizophrenia: a randomized, double-blind, placebo-controlled study. Schizophr Res. 2010;116(2-3):107-117.

35. Hough D, Lindenmayer JP, Gopal S, et al. Safety and tolerability of deltoid and gluteal injections of paliperidone palmitate in schizophrenia. Progr Neuropsychopharmacol Biol Psychiatry. 2009;33(6): 1022-1031.

36. Coppola D, Liu Y, Gopal S, et al. A one-year prospective study of the safety, tolerability and pharmacokinetics of the highest available dose of paliperidone palmitate in patients with schizophrenia. BMC Psychiatry. 2012;12:26

37. Fleischhacker WW, Gopal S, Lane R, et al. A randomized trial of paliperidone palmitate and risperidone long-acting injectable in schizophrenia. Int J Neuropsychopharmacol. 2012;15(1):107-118.

38. Sliwa JK, Bossie CA, Fu DJ, Turkoz I, Alphs L. Long-term tolerability of once-monthly injectable paliperidone palmitate in subjects with recently diagnosed schizophrenia. Neuropsychiatr Dis Treat. 2012;8: 375-385.

39. Gopal S, Xu H, Bossie C, et al. Incidence of tardive dyskinesia: a comparison of long-acting injectable and oral paliperidone clinical trial databases. Int J Clin Pract. 2014;68(12):1514-1522.

40. Alphs L, Mao L, Rodriguez SC, Hulihan J, Starr HL. Design and rationale of the Paliperidone Palmitate Research in Demonstrating Effectiveness (PRIDE) study: a novel comparative trial of once-monthly paliperidone palmitate versus daily oral antipsychotic treatment for delaying time to treatment failure in persons with schizophrenia. J Clin Psych. 2014;75(12):1388-1393.

41. Zhang F, Si T, Chiou CF, et al. Efficacy, safety and impact on hospitalizations of paliperidone palmitate in recent-onset schizophrenia. Neuropsychiatr Dis Treat. 2015;11:657-668.

42. Taylor D, Olofinjana O. Long-action paliperidone palmitate - interim results of an observational study of its effects on hospitalization. Int Clin Psychopharmacol. 2014;29(4):229-234.

43. Schreiner A, Bergmans $\mathrm{P}$, Cherubin $\mathrm{P}$, et al. A prospective flexible-dose study of paliperidone palmitate in non-acute but symptomatic patients with schizophrenia previously unsuccessfully treated with oral antipsychotic agents. Clin Ther. 2014;36(10): 1372-1388.e1

44. Hargarter L, Cherubin P, Bergmans P, et al. Intramuscular long-acting paliperidone palmitate in acute patients with schizophrenia unsuccessfully treated with oral antipsychotics. Progr Neuropsychopharmacol Biol Psychiatry. 2015;58:1-7.

45. Besenius C, Clark-Carter D, Nolan P. Health professionals' attitudes to depot injection antipsychotic medication: a systematic review. J Psychiatr Ment Health Nurs. 2010;17(5):452-462.

46. Lehman AF, Lieberman JA, Dixon LB, et al. Practice guideline for the treatment of patients with schizophrenia, second edition. Am J Psychiatry. 2004;161(2 Suppl):1-56.

47. Velligan DJ, Widen PJ, Sajatovic M, et al. Strategies for addressing adherence problems in patients with serious and persistent mental illness: recommendations from the expert consensus guidelines. J Psychiatr Pract. 2010;16(5):306-324. 
48. Altamura AC, Aguglia E, Bassi M, et al. Rethinking the role of longacting atypical antipsychotics in the community setting. Int $J$ Clin Psychopharmacol. 2012;27(6):336-349.

49. Stahl SM. Long-acting injectable antipsychotics: shall the last be the first? CNS Spectr. 2014;19(1):3-5.

50. Emsley R, Chiliza B, Asmal L, Mashile M, Fusar-Poli P. Long-acting injectable antipsychotics in early psychosis: a literature review. Early Interv Psychiatry. 2013;7(3):247-254.
51. Heres S, Lambert M, Vauth R. Treatment of early episode in patients with schizophrenia: the role of long acting antipsychotics. Eur Psych. 2014;29 Suppl 2:1409-1413.

52. Weyden PJ, Schooler NR, Weedon JC, et al. A randomized controlled trial of long-acting injectable risperidone vs continuation on oral atypical antipsychotics for first-episode schizophrenia patients: initial adherence outcome. J Clin Psychiatry. 2009;70(10):1397-1406.

\section{Publish your work in this journal}

Drug Design, Development and Therapy is an international, peerreviewed open-access journal that spans the spectrum of drug design and development through to clinical applications. Clinical outcomes, patient safety, and programs for the development and effective, safe, and sustained use of medicines are a feature of the journal, which has also been accepted for indexing on PubMed Central. The manuscript management system is completely online and includes a very quick and fair peer-review system, which is all easy to use. Visit http://www.dovepress.com/testimonials.php to read real quotes from published authors.

Submit your manuscript here: http://www.dovepress.com/drug-design-development-and-therapy-journal 